\title{
Paper
}

\section{Characteristics of Electrochemical Electrodes Containing Composite Films of Boron-doped Nanocrystalline Diamond and Amorphous Carbon Prepared using a Coaxial arc Plasma Deposition Method}

\author{
TAKESHI HARA* ${ }^{*}$ \\ TAKUMI TAKENAGA ${ }^{\S}$ \\ Masumi OGishima ${ }^{\dagger}$ \\ Tsuyoshi Yoshitake" \\ Member, \\ Non-member, \\ Member, \\ Non-member
}

\author{
MASAYA ONISHI \\ Non-member \\ Non-member \\ Daisuke Fujimoto ${ }^{\dagger}$ Member
}

(Received June 21, 2019, revised July 12, 2019)

\begin{abstract}
Composite films of boron-doped nanocrystalline diamond and amorphous carbon (B-doped NCD/a-C) were prepared using a coaxial arc plasma deposition (CAPD) method at an unheated substrate temperature without using any reaction gases. The aim of this study is to indicate that the deposited films can be used as high-performance electrochemical electrode materials. Cyclic voltammetry (CV) measurements of the deposited films showed that they exhibit the unique electrochemical characteristics of diamond crystallites. The 4-nitrophenol (4-NP) aqueous solution, which is a recalcitrant substance found in industrial effluents, was degraded via electrolytic treatment using a batch-type system wherein the deposited films were used as anodes. UV-Vis measurements revealed that part of the molecular structure of the 4-NP changed during this reaction. Furthermore, the total organic carbon (TOC) content in the 4-NP aqueous solution decreased as the electrolytic reaction progressed, implying that the degradation of 4-NP proceeded to yield $\mathrm{CO}_{2}$. The results reveal that the B-doped NCD/a-C films prepared using CAPD can be used as high-performance electrochemical electrode materials in industrial water treatment.
\end{abstract}

Keywords: Nanocrystalline diamond films, Coaxial Arc plasma, electrochemical electrodes, water treatment electrodes

\section{Introduction}

Conductive polycrystalline diamond (PCD) films that are doped with impurities including boron (B) exhibit unique and advantageous chemical characteristics such as a wide potential window, extremely low background current, and high chemical stability in various solutions. Therefore, they are expected to be useful as electrode materials in wastewater treatment to facilitate the degradation of the recalcitrant substances, such as phenolic pollutants [1] [4], which are difficult to degrade using electrochemical treatments via conventional noble-metal electrodes such as $\mathrm{Pt}$ elec-

\footnotetext{
* Corresponding author: hara@ariake-nct.ac.jp

$\dagger$ National Institute of Technology (KOSEN), Ariake College, 150, Higashihagio-machi, Omuta, Fukuoka, Japan 836-8585

¥ Hitachi High-Tech Kyushu Corporation, 1892-1, Tegama, Omuta, Fukuoka, Japan 836-0004

$\S$ ROHM Co., Ltd., 579-32, Higashi Shiokoji-cho, Karasuma Nishiiru, Shiokoji-dori, Shimogyo-ku, Kyoto, Japan 600-8216

II Kyoto University, Kyoto University Katsura, Kyoto Nishikyo-ku, Kyoto, Japan 615-8510

" Kyushu University, 6-1, Kasuga-koen, Kasuga, Fukuoka, Japan $816-8580$
}

trodes, wherein the electrolysis of water occurs preferentially because of the electrodes' relatively narrow potential window compared to those of conductive PCD electrodes. They have also been applied as electrodes for electrosynthesis [5] and highly sensitive electrochemical sensors [6] [7] in industrial fields. Diamond films containing conductive PCD also show potential for other industrial applications such as electronic devices [8] [9] and hard coatings [10][11] because of their superior electrical and mechanical characteristics.

Diamond films are mainly fabricated using chemical vapor deposition (CVD). However, the proposed methods [3] [4][6] [11] require (i) a general substrate temperature above approximately $800{ }^{\circ} \mathrm{C}$, (ii) pretreatment of the substrates using diamond powder (i.e., seeding), and (iii) the presence of a reaction gas to enhance the diamond growth and conductivity; moreover, both the experimental equipment and film materials are expensive. Hence, alternative methods without such limitations would accelerate the industrial application of diamond films in various fields. However, addressing all of these issues is challenging. 
Recently, nanocrystalline diamond/amorphous carbon composite (NCD/a-C) films have gained considerable attention because of their unique characteristics including a low coefficient of friction [12], high thermal stability [13], and large optical absorption coefficient [14]. NCD with crystallite diameters of less than 10 $\mathrm{nm}$ is called ultrananocrystalline diamond (UNCD) [15] and exhibits superior mechanical, physical, and chemical properties. Films containing UNCD are expected to have extensive industrial applications [12] [14]. Such films are generally fabricated using CVD based on a long history of studies of diamond films [12] [15], but these methods suffer from the same limitations as mentioned above. By contrast, only a few studies have reported the fabrication of such films by physical vapor deposition (PVD).

Although there have been few reports about NCD growth by a coaxial arc plasma deposition (CAPD) method, which is a type of PVD, this approach has been steadily gaining popularity in recent years for various industrial applications such as electronic devices [18][19] and hard coatings [20]. However, the growth of single-crystalline or polycrystalline diamond by CAPD remains extremely difficult. Hanada et al. reported that the plasma used in the CAPD process for the growth of NCDs contains $\mathrm{C}^{+}$ions and a high density of energetic species [16]. Y. Yao et al. also reported that diamond nucleation is induced by the bombardment of highly energetic $\mathrm{C}^{+}$ions onto an a-C matrix [17]. Thus, the impact of large numbers of energetic carbon species on the substrate leads to a supersaturated condition for the growth of diamond crystallites. As such, the growth of NCD by CAPD in a vacuum may be possible even when the substrate temperature is low. In our previous study, we successfully grew NCD/a-C and boron (B)doped NCD/a-C films by CAPD at room temperature under a vacuum [21] [22]. These NCD growth conditions differ greatly from those needed for CVD. These B-doped NCD/a-C films were shown to have superior electrochemical characteristics that are comparable to those of commercially available boron doped diamond electrodes. In addition, the experimental equipment needed for CAPD is readily available and relatively inexpensive.

Moreover, we have previously shown that the deposited films can be used as electrodes for an electrolytic reaction that degrades 4-nitrophenol (4-NP) [23]. 4-NP is one of the recalcitrant substances in industrial effluents and is highly toxic to humans and the environment. Conductive PCD is considered the leading candidate for the electrolytic degradation of 4-NP [24] [25]. However, these electrodes have only been fabricated by CVD.

In this study, we used a CAPD method to grow Bdoped NCD/a-C films. Herein, we demonstrate, for the first time, the many attractive features and industrial usefulness of NCD growth by CAPD. We characterize the effectiveness of the fabricated films on the degra-

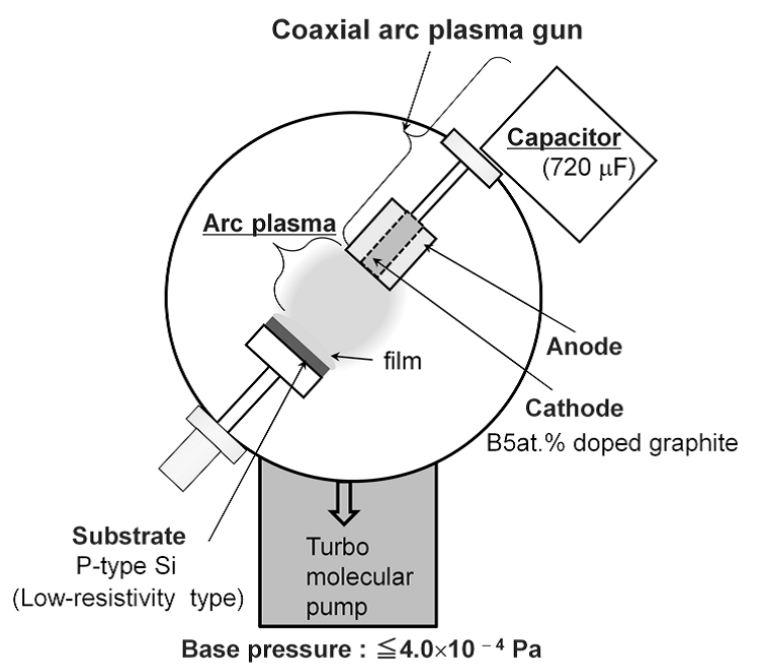

Figure 1: Schematic of the film deposition apparatus.

dation of 4-NP by UV-Vis spectrophotometry and total organic carbon (TOC) measurements of the residual solution following the electrolytic reaction of the 4-NP aqueous solution. Hence, we demonstrate the performance of the deposited films absolutely as an electrode for electrolytic reactions, specifically the degradation of 4-NP to $\mathrm{CO}_{2}$. This investigation will demonstrate the utility of B-doped NCD/a-C films prepared by CAPD for industrial applications in terms of the electrochemical performance as compared to conductive PCD electrodes. In addition, we discuss the fabrication conditions and fabrication cost of the B-doped NCD/a-C films prepared by CVD compared with those of conductive PCD electrodes.

\section{Experimental Equipment}

Figure 1 shows a schematic of the apparatus used for film deposition. B-doped NCD/a-C films with a thickness of approximately $1.4 \mu \mathrm{m}$ were deposited by CAPD under a vacuum below $10^{-4} \mathrm{~Pa}$ onto low-resistivity $\mathrm{p}$ type Si (100) substrates. During the deposition, the substrate temperature was maintained at room temperature. The distance between the substrate and the target was $20 \mathrm{~mm}$. An arc voltage of $100 \mathrm{~V}$ was applied to an arc plasma gun (ADVANCE RIKO, Inc. APG-1000) equipped with a $720 \mu \mathrm{F}$ capacitor. The repetition rate of pulsed discharges was $5 \mathrm{~Hz}$. A graphite target containing 5 at. $\%$ B was used.

The potential window and background current were measured by cyclic voltammetry (CV) with the electrodes immersed in an aqueous electrolytic solution of $1.0 \mathrm{~mol} / \mathrm{L} \mathrm{H}_{2} \mathrm{SO}_{4}$. The deposited films, $\mathrm{Pt}$, and $\mathrm{Ag} / \mathrm{AgCl}$ were used as the working electrodes, counter electrode, and reference electrode, respectively.

The electrolytic treatment of 4-NP aqueous solutions was conducted using a batch-type electrolytic system with the deposited films as the anode and a stainless steel electrode as the cathode, as shown in Figure 2. The distance between these electrodes was $5.0 \mathrm{~mm}$. The 


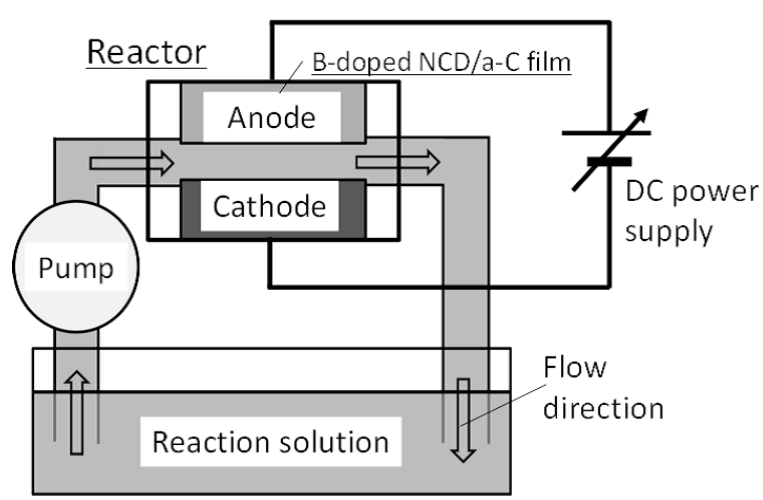

Figure 2: Schematic of the batch-type electrolytic system.

concentration of the $\mathrm{Na}_{2} \mathrm{SO}_{4}$ electrolytic solution was $0.20 \mathrm{~mol} / \mathrm{L}$. A $4-\mathrm{NP}$ aqueous solution $(25 \mathrm{~mL})$ containing a TOC concentration of $100 \mathrm{mg} / \mathrm{L}$ was prepared and run through upward flow at $0.60 \mathrm{~L} / \mathrm{h}$. The current density was $1.5 \mathrm{~A} / \mathrm{dm}^{2}$. The total electrolytic treatment time was $60 \mathrm{~min}$. A $1.0 \mathrm{~mL}$ sample of the electrolytically treated solution was removed using a syringe every 20 min. They also mixed with a $1.0 \mathrm{~mol} / \mathrm{L}$ carbonate buffer solution $\left(\mathrm{Na}_{2} \mathrm{CO}_{3}\right.$ and $\left.\mathrm{NaHCO}_{3}\right)$ adjusted to $\mathrm{pH} 9.8$ for the UV-Vis measurement. The absorbance and TOC concentration of solution after the electrolytic reaction were estimated by using a UV-Vis spectrophotometer (Shimadzu Corporation UV-2550PC) and a TOC measurement system (Shimadzu Corporation TOC-VCSN), respectively.

\section{Results and Discussion}

First, the CV characteristics of the prepared B-doped NCD/a-C film were compared with those of a conductive PCD electrode and a Pt electrode, which are commercially available electrodes that are generally used in electrolytic reactions. The typical CV characteristics of the three samples are shown in Fig. 3. The inset shows the data collected from the conductive PCD electrode and the B-doped NCD/a-C film magnified along the current-density axis. The B-doped NCD/a-C films prepared by CAPD exhibited a wide potential window and an extremely low background current, which are fundamental electrochemical characteristics of conductive PCD electrodes and consistent with the measured CV characteristics of the PCD electrode in this study. On the other hand, the Pt electrode, which is one of the noble-metal electrodes that are commonly used in electrolytic reactions, was inferior compared with the conductive PCD electrode and B-doped NCD/a-C film.

The potential window is a potential region in which electrochemical measurements can be performed in a variety of combinations of solvent, supporting electrolyte, and electrode. The wide potential window observed in B-doped NCD/a-C films prepared by CAPD and conductive PCD electrodes can preferentially advance the redox reactions of various substances prior

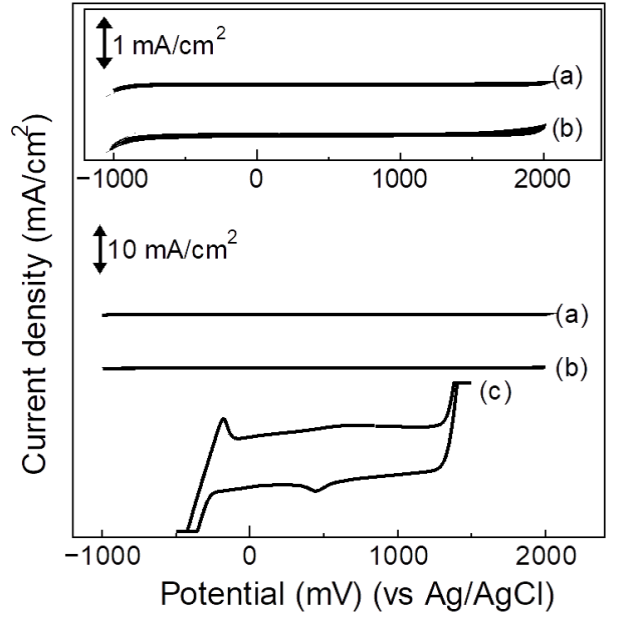

Figure 3: Typical CV characteristics of (a) a conductive PCD electrode, (b) a B-doped NCD/a-C film, and (c) a Pt electrode.

to the generation of oxygen and hydrogen by the electrolysis of water. Thus, this property is ideal for water treatment electrodes used to degrade recalcitrant substances. The extremely low background current observed in B-doped NCD/a-C films prepared by CAPD and conductive PCD electrodes facilitate highly sensitive detection of reaction substances using the electrochemical sensor because it leads to a high signal-tonoise $(\mathrm{S} / \mathrm{N})$ ratio. These findings indicate that the $\mathrm{B}$ doped NCD/a-C films prepared by CAPD have strong potential as electrode materials for degrading 4-NP by an electrolytic reaction.

Next, the degradation of 4-NP was conducted by an electrolytic reaction using a conductive PCD electrode, a B-doped NCD/a-C film, and a Pt electrode as the anode. Fig. 4 shows the UV-Vis spectra of the 4-NP aqueous solutions taken every 20 min during the electrolytic reaction. The characteristic peak of $4-\mathrm{NP}$ at $400 \mathrm{~nm}$ decreased over the reaction period with all electrodes, which is generally considered to indicate that the 4-NP was degraded into another substance [26] [27]. The rate of degradation of 4-NP was higher with the conductive PCD electrode and B-doped NCD/a-C film than with the Pt electrode. The change in the absorbance between 20 and 40 min with the Pt electrode was negligible, indicating that the degradation reaction of $4-\mathrm{NP}$ did not progress during this period.

Fig. 5 shows the rate of change in the peak intensity at $400 \mathrm{~nm}$ (attributed to $4-\mathrm{NP}$ ) at each time point in the electrolytic reaction for each electrode. The conductive PCD electrode and B-doped NCD/a-C film demonstrated particularly significant changes during the electrolytic treatment: the peak at $400 \mathrm{~nm}$ decreased by approximately $33.8 \%$ and $28.9 \%$, respectively, after 60 min. On the other hand, the rate of decrease in the peak intensity was only about $17.7 \%$ after 60 min using the Pt electrode, indicating that the degradation capability 


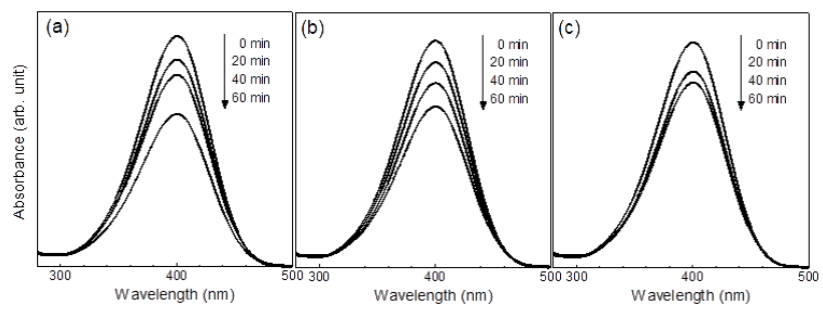

Figure 4: UV-Vis absorption spectra of aqueous 4-NP during the 60 min electrolytic treatment using (a) a conductive PCD electrode, (b) a B-doped NCD/a-C film, and (c) a Pt electrode as the anode.

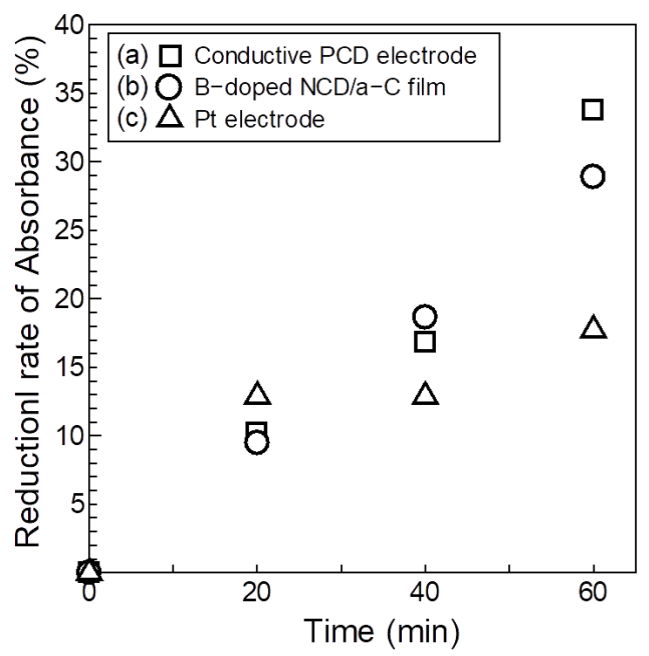

Figure 5: Reduction of the peak intensity at $400 \mathrm{~nm}$ due to 4-NP degradation at several time points during the electrolytic reaction using (a) a conductive PCD electrode, (b) a B-doped NCD/a-C film, and (c) a Pt electrode as the anode.

of the electrode for 4-NP was inferior to those of the conductive PCD electrode and B-doped NCD/a-C film.

$\mathrm{P}$. Cañizares et al. reported the complex degradation mechanism of 4-NP via an electrolytic reaction using a conductive PCD as an anode [24]. The nitro group is released from the aromatic group in the first stage; these organic compounds are first oxidized to maleic and oxalic acids (which are carboxylic acids) and finally oxidized to carbon dioxide $\left(\mathrm{CO}_{2}\right)$ [24] [27]. Although the UV-Vis spectra can indicate that the structure of 4-NP has collapsed, they cannot show whether the degradation process has proceeded to $\mathrm{CO}_{2}$. However, it is important to confirm that the degradation progressed to $\mathrm{CO}_{2}$ because maleic and oxalic acids are also toxic to humans and the environment. Therefore, the TOC content was measured from the reaction samples that were collected as described above, and the removal rate of TOC was estimated for each electrolytic reaction time. If the 4-NP is degraded to $\mathrm{CO}_{2}$, it will be released into the air. As a result, the TOC amount in the 4-NP aqueous solution should decrease. Fig. 6 shows the relation between the electrolytic reaction time and the TOC removal rate

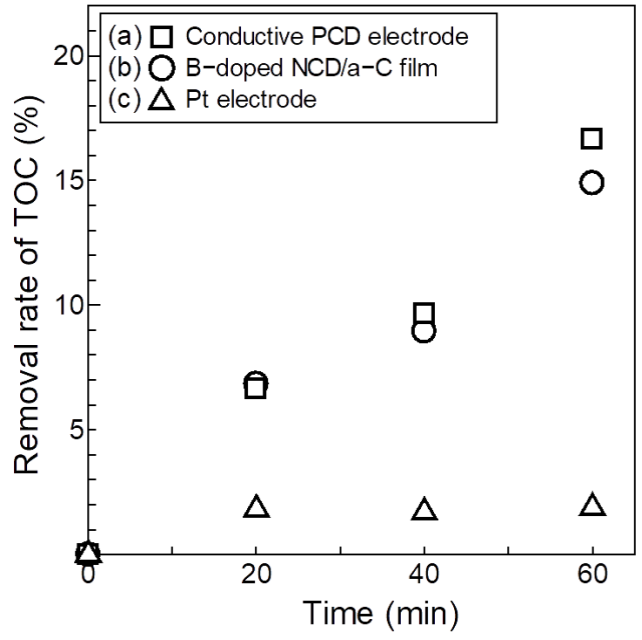

Figure 6: Relation between the electrolytic reaction time and the TOC removal rate with (a) a conductive PCD electrode, (b) a B-doped NCD/a-C film, and (c) a Pt electrode as the anode.

using the conductive PCD electrode, B-doped NCD/a$\mathrm{C}$ film, and $\mathrm{Pt}$ electrode as the anode. The TOC removal rate with the B-doped NCD/a-C film was similar to that using the conductive PCD electrode throughout the electrolytic reaction time and about $1.8 \%$ lower at $60 \mathrm{~min}$. However, the performance of the B-doped NCD/a-C film was sufficient as an electrode for the electrolytic reaction to degrade 4-NP.

Furthermore, the TOC removal rate using the Bdoped NCD/a-C film and the conductive PCD electrode varied linearly with the electrolytic reaction time. In other words, the reaction kinetics generally follow the model $\ln \left(\mathrm{C} / \mathrm{C}_{0}\right)=-k t$, where $k$ is the kinetic rate constant, $t$ is the electrolytic reaction time, $\mathrm{C}_{0}$ is the initial TOC concentration before the electrolytic reaction, and $C$ is the TOC concentration after the electrolytic reaction had progressed for a certain amount of time. The $k$ value was estimated by fitting a straight line to the $\ln \left(\mathrm{C} / \mathrm{C}_{0}\right)$ versus electrolytic time data, as shown in Fig. 7. The $k$ value of the B-doped NCD/a-C film was approximately the same as that of the conductive PCD film, further indicating that the prepared B-doped NCD/a-C film can function as an anode in the electrolytic reaction for the degradation 4-NP like the conductive PCD electrodes. Moreover, it can be predicted as these electrode materials will completely degrade the 4-NP if the same electrolytic reaction was allowed to progress for a longer reaction time. This result will be reported in detail elsewhere.

In contrast, when the Pt electrode was used as the anode, the rate of decrease in the TOC content was below $2 \%$ after $60 \mathrm{~min}$ of electrolytic reaction time, as shown in Fig. 6(c). Thus, while Pt can effectively degrade the 4-NP, its degradation performance is extremely weak, and the degradation does not proceed to the $\mathrm{CO}_{2}$ product. Therefore, Pt electrodes cannot render the 4-NP 


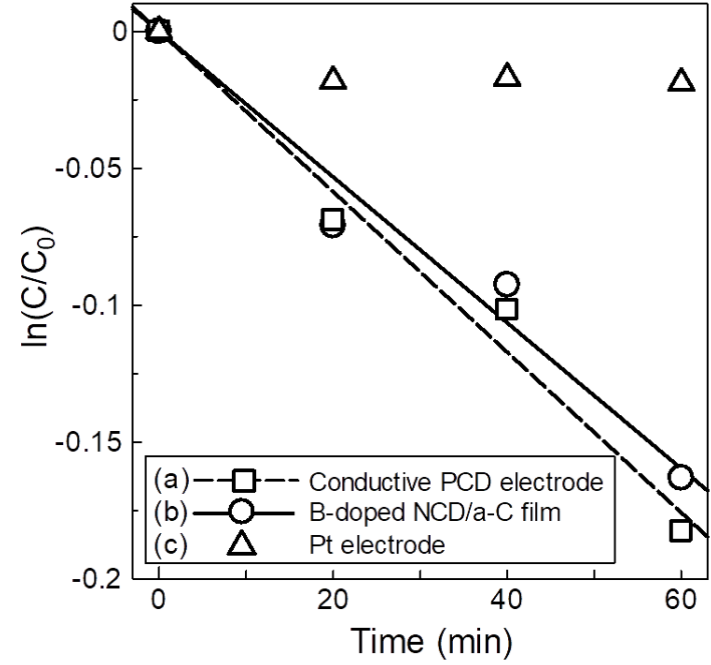

Figure 7: Relation between $\ln \left(\mathrm{C} / \mathrm{C}_{0}\right)$ and the electrolytic reaction time with (a) a conductive $\mathrm{PCD}$ electrode, (b) a B-doped NCD/a-C film, and (c) a Pt electrode as the anode.

harmless; thus, they are considered unfit to degrade 4NP in wastewater treatment applications.

In the preparation of B-doped NCD/a-C films by the CAPD method, no explosive or harmful gases are used as reaction gases. Further, the fabrication was performed with the substrate at room temperature. These conditions are more reasonable and practical than those of CVD, which is the most commonly used preparation method for B-doped NCD/a-C films and conductive PCD films. Moreover, the film growth rate using the proposed method is about one order of magnitude higher than that of the standard CVD process for diamond growth [29] [31]. These characteristics allow for savings on materials and human labor and can facilitate high productivity in industrial applications. Moreover, the experimental equipment needed for CAPD is more reasonable than that for CVD; even the high-end model of the CAPD system is more than $1 / 2$ less expensive than the laboratory configuration needed for CVD.

\section{Conclusion}

Based on these findings of this study, it was concluded that the B-doped NCD/a-C films prepared by the CAPD method are exceptional as anodes for electrolytic reactions although their degradation capability for 4-NP was slightly inferior compared with that of conductive PCD electrodes. The continued industrial development of B-doped NCD/a-C films is expected to have a great impact and economic ripple effect on not only the water treatment industry but also various engineering fields as electrode materials. These films are also expected to be useful not only in electrochemical applications but also in mechanics and electronics engineering.

In future studies, we will further characterize the Bdoped NCD/a-C films prepared by CAPD by evaluating their electrochemical stability over repeated electrolytic reactions and estimating the total power requirements for the complete degradation of 4-NP.

\section{Acknowledgment}

This study was partially supported by Kurita Water and Environment Foundation. The UV-Vis absorption spectra measurement and the TOC amount measurement were performed at Applied Chemistry Course, Department of Creative Engineering, National Institute of Technology (KOSEN), Ariake College. The authors gratefully thank Dr. Isao Joko who is a former professor at National Institute of Technology, Ariake College for his technical advice concerning waste water treatment technique.

\section{References}

[1] M. Panizza and G. Cerisola, "Application of Diamond Electrodes to Electrochemical Processes", Electrochimica Acta, Vol.51, pp. 191-199, 2005.

[2] Gabriel F. Pereira, Romeu C. Rocha-Filho, Nerilso Bocchi and Sonia R. Biaggio, "Electrochemical Degradation of Bisphenol A using a Flow Reactor with a Borondoped Diamond Anode", Chemical Engineering Journal, Vol.198-199, pp. 282-288, 2012.

[3] J. Iniesta, P. A. Michaud, M. Panizza, G. Cerisola, A. Aldaz and Ch. Comininellis, "Electrochemical Oxidation of Phenol at Boron-doped Diamond Electrode", Electrochimica Acta, Vol. 46, pp. 3573-3578, 2001.

[4] M. A. Rodrigo, P. Cañizares, A. Sánchez-Carretero and C. Sáez, "Use of Conductive-diamond Electrochemical Oxidation for Wastewater Treatment", Catalysis Today, Vol.151, pp. 173-177, 2010.

[5] S. R. Waldvogel and B. Elsler, "Electrochemical Synthesis on Boron-doped Diamond", Electrochimica Acta, Vol.82, pp. 434-443, 2012.

[6] T. Kondo, K. Sakai, T. Watanabe, Y. Einaga and M. Yuasa, "Electrochemical Detection of Lipophilic Antioxidants with High Sensitivity at Boron-doped Diamond Electrode", Electrochimica Acta, Vol.95, pp. 205-211, 2013.

[7] K. L. Soh, W. P. Kang, J. L. Davidson, Y. M. Wong, A. Wisitsora-at, G. Swain and D. E. Cliffel, "CVD Diamond Anisotropic Film as Electrode for Electrochemical Sensing”, Sensors and Actuators B, Vol.91, pp. 39-45, 2003.

[8] K. Ueda, M. Kasu, Y. Yamauchi, T. Makimoto, M. Schwitters, D. J. Twitchen, G. A. Scarsbrook and S. E. Coe, "Diamond FET using High-quality Polycrystalline Diamond with fT of $45 \mathrm{GHz}$ and fmax of $120 \mathrm{GHz}$, IEEE Electron Device Letters, Vol.27, No.7, pp. 570-572, 2006.

[9] M. -A. Pinault-Thaurya, T. Tillocher, N. Habka, D. Kobor, F. Jomard, J. Chevallier and J. Barjon Yang, "n-Type CVD Diamond: Epitaxy and Doping”, Materials Science and Engineering B, Vol.176, pp. 1401-1408. 2011. 
[10] N. Savvides and T. J. Bell, “ Hardness and Elastic Modulus of Diamond and Diamond-like Carbon Films", Tin Solid Films, Vol.228, pp. 289-292, 1993.

[11] M. S. Raghuveer, S. N. Yoganand, K. Jagannadham, R. L. Lemaster and J. Bailey, "Improved CVD Diamond Coatings on WC-Co Tool Substrates", Wear, Vol.253, pp. 11941206, 2002.

[12] A. Erdemir, G. R. Fenske, A. R. Krauss, D. M. Gruen, T. McCauley and R. T. Csencsits, "Tribological Properties of Nanocrystalline Diamond Films", Surface and Coatings Technology, Vol.120-121, pp. 565-572, 1999.

[13] V. Ralchenko, S. Pimenov, V. Konov, A. Khomich, A. Saveliev, A. Popovich, I. Vlasov, E. Zavedeev, A. Bozhko, E. Loubnin and R. Khmelnitski, "Nitrogenated Nanocrystalline Diamond Films: Thermal and optical properties", Diamond \& Related Materials, Vol.16, pp. 2067-2073, 2007.

[14] M. Sobaszek, Ł. Skowrośki, R. Bogdanowicz, K. Siuzdak, A. Cirocka, P. Zieba, M. Gnyba, M. Gnyaba, M. Naparty, Ł. Gołuński, P. Płotka, "Optical and Electrical Properties of Ultrathin Transparent Nanocrystalline Boron-doped Diamond Electrodes", Optical Materials, Vol. 42, pp. 24$34,2015$.

[15] O. A. Williams, M. Daenen, J. D'Haen, K. Haenen, J. Maes, V. V. Moshchalkov, M. Nesl 'adek, D. M. Gruen, "Comparison of the Growth and Properties of Ultrananocrystalline Diamond and Nanocrystalline Diamond", Diamond and Related Materials, Vol. 15, pp. 654-658, 2006.

[16] K. Hanada, T. Yoshitake, T. Nishiyama and K. Nagayama, "Time-resolved Spectroscopic Observation of Deposition Processes of Ultrananocrystalline Diamond/Amorphous Carbon Composite Films by using a Coaxial Arc Plasma Gun", Japanese Journal of Applied Physics, Vol. 49, No. 8, pp. 08JF091-08JF094, 2010.

[17] Y. Yao, M. Y. Liao, T. Kőhler, T. Frauenheim, R. Q. Zhang, Z. G. Wang, Y. Lifshitz, S. T. Lee, "Diamond Nucleation by Energetic Pure Carbon Bombardment", Physical Review B, Vol. 72, pp. pp. 0354021-0354025, 2005.

[18] A. Zkria, Y. Katamune and T. Yoshitake, "Effects of Nitrogen Doping on the Electrical Conductivity and Optical Absorption of Ultrananocrystalline Diamond/Hydrogenated Amorphous Carbon Films prepared by Coaxial Arc Plasma Deposition", Japanese Journal of Applied Physics, Vol. 55, No. 7S2, pp. 07LE011-07LE014, 2016.

[19] A. Zkria, H. Gima, M. Shaban and T. Yoshitake, "Electrical Characteristics of Nitrogen-Doped Ultrananocrystalline Diamond/Hydrogenated Amorphous Carbon Composite Films Prepared by Coaxial Arc Plasma Deposition", Applied Physics Express, Vol. 8, pp. 0951011-0951013, 2015.

[20] H. Naragino, M. Egiza, A. Tominaga, K. Murasawa and H. Gonda, M. Sakurai, and T. Yoshitake, "RoomTemperature Hard Coating of Ultrananocrystalline Diamond/Nonhydrogenated Amorphous Carbon Composite
Films on Tungsten Carbide by Coaxial Arc Plasma Deposition", Japanese Journal of Applied Physics, Vol. 55, No. 3, pp.0303021-0303024, 2016.

[21] T. Hara, Y. Nojiri, K. Hanada and T. Yoshitake, "Detection Methods of Diamond Diffraction Peaks in Ultrananocrystalline Diamond/Amorphous Carbon Composite Films by X-Ray Diffraction Measurement with Semiconductor Counter Detector", Japanese Journal of Applied Physics, Vol.54, No. 10, pp. 1080021-1080023, 2015.

[22] T. Hara, M. Onishi, D. Fujimoto and T. Yoshitake, "Electrochemical Characteristics Of Boron-Doped Ultrananocrystalline Diamond/Amorphous Carbon Composite Films Fabricated by Coaxial Arc Plasma Deposition", The Japanese Journal of the Institute of Industrial Applications Engineers", Vol. 4, No.1, pp. 31-32, 2016. [in Japanese]

[23] T. Takenaga, M. Onishi, D. Fujimoto, Y. Nojiri and T. Hara, "Electrolytic Treatment Characteristics of BoronDoped Nanocrystalline Diamond/Amorphous Carbon Composite Films Prepared by Coaxial Arc Plasma Deposition”, Proceedings of the 5th IIAE International Conference on Industrial Application Engineering 2017, pp. 45-50, 2017.

[24] P. Cañizares, C. Sáez, J. Lobato, and M. A. Rodrigo, "Electrochemical Treatment of 4-NitrophenolContaining Aqueous Wastes using Boron-Doped Diamond Anodes", Industrial \& Engineering Chemistry Research, Vol. 43, No. 9, pp. 1944-1951, 2004.

[25] X. Zhu and J. Ni, "The Improvement of Boron-Doped Diamond Anode System in Electrochemical Degradation of P-Nitrophenol by Zero-Valent Iron”, Electrochimica Acta, Vol. 56, pp. 10371-10377, 2011.

[26] K. Kuroda, T. Ishida and M. Haruta, "Reduction of 4nitrophenol to 4-aminophenol over Au Nanoparticles Deposited on PMMA", Journal of Molecular Catalysis A: Chemical, Vol.298, pp. 7-11, 2009.

[27] B. Vellaichamy, P. Periakaruppan and J. Thomas, "Synthesis of AuNPs@RGO Nanosheets for Sustainable Catalysis Toward Nitrophenols Reduction", UltrasonicsSonochemistry, Vol. 48, pp. 362-369, 2018.

[28] P. Cañizares, M. Díaz, J. A. Domínguez, García-Gómez and M. A. Rodrigo, "Electrochemical Oxidation of Aqueous Phenol Wastes on Synthetic Diamond Thin-Film Electrodes", Industrial \& Engineering Chemistry Research, Vol.41, No.17, pp.4187-4194, 2002.

[29] G. Cicala, P. Bruno, F. Bénédic, F. Silva, K. Hassouni and G. S. Senesi, "Nucleation, Growth and Characterization of Nanocrystalline Diamond Films", Diamond and Related Materials, Vo. 14, pp. 421-425, 2005.

[30] D. Zhou, T. G. McCauley, L. C. Qin, A. R. Krauss and D. M. Gruen, "Synthesis of Nanocrystalline Diamond Thin Films from an Ar-CH4 Microwave Plasma”, Journal of Applied Physics, Vol. 83, No. 1, pp. 540-543, 1998.

[31] M. Hiramatsua, C. H. Lau, A. Bennett and J. S. Foord, "Formation of Diamond and Nanocrystalline Diamond 
Films by Microwave Plasma CVD", Thin Solid Films, Vol. 407, pp. 18-25, 2002.

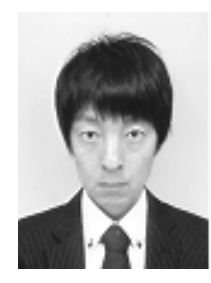

Takeshi Hara (Member) was born in Saga, Japan, on October 4th, 1977. He received his Dr. Eng. degree from Kyushu University in 2005 , and is presently an associate professor at National Institute of Technology (KOSEN), Ariake College. He has worked on research of carbon films and their industrial apprication. He is member of IIAE, JSAP, and JSWE.

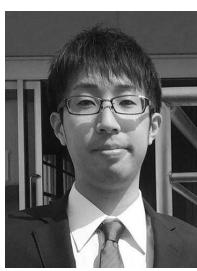

Masaya Onishi (Non-member) was born in Saga, Japan, on October 12th, 1994. He received his B.S. degree in engineering from National Institute of Technology (KOSEN), Ariake College in 2017, and is presently a engineer at Hitachi High-Tech Kyushu Corp.

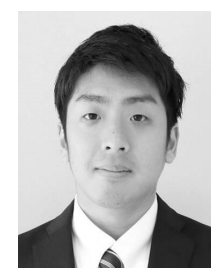

Takumi Takenaga (Non-member) was born in Fukuoka, Japan, on September 7th, 1995. He received his B.S. degree in engineering from National Institute of Technology (KOSEN), Ariake College in 2018, and is presently a engineer at ROHM Co., Ltd.

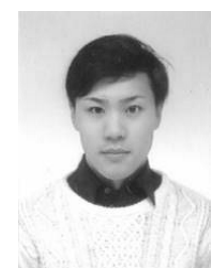

Yuta Inoue (Non-member) was born in Fukuoka, Japan, on october 4th, 1996. He received his B.S. degree in engineering from National Institute of Technology (KOSEN), Ariake College in 2019, and is presently a master course student in Department of Energy and Hydrogen Chemistry, Kyoto university.

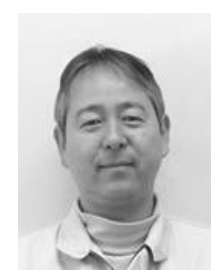

Masumi Ogishima (Member) was born in Fukuoka, Japan, on April 17th, 1975. He is a Technical Senior staff at National Institute of Technology (KOSEN), Ariake College. He has worked on construction of measurement systems using micro computer control and fundamental electronic circuit. He is member of IIAE.

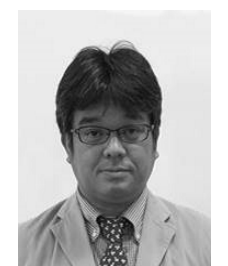

Daisuke Fujimoto (Member) was born in Ehime, Japan, on December 23th, 1975. He received his $\mathrm{Ph} . \mathrm{D}$. degree in human and enviromental studies from Kyoto University in 2003 , and is presently an associate professor at National Institute of Technology (KOSEN), Ariake College. He has worked on research of waste water treatment using an electrolytic reaction. He is member of IIAE, CSJ, and JSWE.

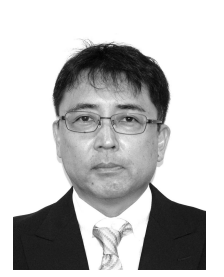

Tsuyoshi Yoshitake (Non-member) was born in Fukuoka, Japan, on December 25th, 1968. He received his Dr. Eng. degree in electronic engineering from Kyushu Institute of Technology in 1998, and is presently an associate professor at the Interdisciplinary Graduate School of Engineering Science, Kyushu University. He has worked on research of electronic materials in thin film and their applications to electronic device. He is member of JSAP, MSJ, and JNDF. 